\title{
An Expert System for building a Cognitive and Career Prediction model based on N-Coin Puzzle Game
}

\author{
V. Chandra Prakash ${ }^{1}$, J.K.R. Sastry ${ }^{2 *}$, B. Tirapathi Reddy ${ }^{3}$ J. S. Ravi Teja ${ }^{4}$, A. Bala Venkatesh ${ }^{5}$, M. S. K. Vamsi Varma ${ }^{6}$ \\ ${ }^{1}$ Koneru Lakshmaiah Education Foundation, Vaddeswaram, AP, India, vchandrap@kluniversity.in \\ ${ }^{2}$ Koneru Lakshmaiah Education Foundation, Vaddeswaram, AP, India, drsastry@kluniversity.in, \\ ${ }^{3}$ Koneru Lakshmaiah Education Foundation, Vaddeswaram, AP, India, tirapathireddyb@kluniversity.in, \\ ${ }^{4}$ Koneru Lakshmaiah Education Foundation, Vaddeswaram, AP, India, syamrt@ gmail.com, \\ ${ }^{5}$ Koneru Lakshmaiah Education Foundation, Vaddeswaram, AP, India, addankibalanaidu@gmail.com, \\ ${ }^{6}$ Koneru Lakshmaiah Education Foundation, Vaddeswaram, AP, India,mskvv13@gmail.com
}

\begin{abstract}
Career prediction is an essential aspect for an undergraduate student during his/her academic life. The academic grades obtained for different courses studied by a student are useful to predict the right career(s) for the student. Apart from theoretical subjects, the marks obtained in subjects like Communication, Aptitude, reasoning, etc. are also useful for predicting the appropriate career(s). Moreover, the authors proposed that evaluating the psychological factors viz. logical thinking, intelligence, patience and perseverance, learning ability, etc. of a student is highly essential to predict the most appropriate career(s) for a student. Playing games and solving puzzles are two powerful techniques that are useful to evaluate some of the aforesaid psychological factors. An expert system designed that creates n-coin puzzles for a student and the students' attempts to solve them all. The expert system evaluates the levels of psychological factors viz. logical thinking, patience, and perseverance and learning ability of a student both quantitatively and qualitatively. This system builds a cognitive model of the student. This system maintains a career(s) table wherein each job and the corresponding minimum levels of psychological factors of a student that are needed to perform that job successfully. The system explores and finds suitable jobs for a student basing on his/her cognitive model.
\end{abstract}

Keywords: N-coin puzzle, expert systems, evaluating psychological factors, solving puzzles, career prediction, cognitive model, logical thinking, patience and perseverance, learning ability.

\section{INTRODUCTION}

In any institution/university, the human experts' viz. teachers, counsellors, campus placement coordinator, etc. will try to evaluate the academic knowledge, communication skills, etc. of a student and attempt to predict suitable career(s) for the student. But, in general, they do give little importance to the psychological factors of a student like patience and perseverance, learning ability, etc. Eventually, when a student gets a job, he/she may succeed or fail in doing that job. The most important reason for the failure of the student could be that his/her psychological factors do not suit to the psychological factors expected in a person doing that job. Hence it is a better idea to evaluate and consider the psychological elements of a student while searching for a suitable career(s) for a student. When a student plays a game or solves a puzzle, we can evaluate the levels of psychological factors of a student. There are many ways to assess psychological factors like IQ tests, Quizzes, Logical Reasoning, Aptitude, etc. In this research work, an expert system designed that creates n-Coin Puzzles for a student. By solving the $\mathrm{n}$-Coin puzzle, evaluating psychological factors becomes pure, but assessing logical thinking by solving puzzles is a compelling way.

\section{N-Coin Puzzle}

The $\mathrm{n}$-Coin puzzle is a puzzle that is helpful to evaluate the psychological factors of the student's viz. logical thinking, patience and perseverance, learning ability, etc. The guidelines for solving coin puzzle are as follows:

1. N-coin puzzle consists of 5 levels viz. 4-coin puzzle, 5-coin puzzle, 6-coin puzzle, 7-coin puzzle, 8 -coin puzzle.

2. Initially, a student can solve only the 1 st level, i.e., 4-coin puzzle, and the remaining levels are locked. If he/she completes the current level, then the next level will be unlocked.

3. In the n-coin puzzle, (n-1) coins are identical in weights except for one coin, which is lighter or heavier than others.

4. A Physical balance is provided to weigh the coins. The Physical balance consists of two pans, i.e., left pan and right pan. Any number of coins can select 
in any container. But selected coin can choose not again in the other pan. Physical balance gives the result of UP/DOWN by comparing the weights of coins selected from in the container (s).

5. A player should identify the odd coin by using the provided physical balance in 3 weightings.

6. The player should solve three times to assess his/her score on that level.

7. The player should solve three times consecutively in 3 steps to complete the level and to unlock the successive level.

\section{Expert System}

An expert system is best for career prediction to evaluate the psychological factors viz. logical thinking, learning ability, decision making, patience, and perseverance, etc. Student can solve puzzles to assess his/her psychological factors to predict a suitable career(s).

\section{Importance of evaluating psychological factors}

Evaluating psychological factors play a crucial role in career(s) prediction. Based on the suggested job (s) by the expert system, the student selects his/her elective courses or career-related courses for his/her betterment in their career(s). In many companies, assessing psychological factors by tests, quizzes, etc. but assessing them using game playing and puzzle-solving is easy.

Chandra Prakash et al.[15] pointed out that evaluating psychological factors using games or puzzles are the best way. In this paper, the authors proposed that a game called 'Sodoku' is best to assess the Speed of problem-solving, Problem-solving ability, learning ability, etc. of a student.

Sripath Roy et al. [16] pointed out that evaluating students in all different aspects is useful to recommend/decide the right job which suits them.

\section{Problem Definition}

An expert system " $n$-Coin Puzzle" puzzle-solving is designed and developed on java using java interface (GUI). The student solves the puzzle, and the system suggests a suitable career(s) by evaluating the psychological factors.

\section{RELATED WORK}

Selecting a proper career(s) is very important for a student for a better job. Generally, a human expert in that field suggests a career(s) options to the students based upon their academic standards. But a human expert can also make errors in recommending the most suitable job (s) for students. The expert system can build using AI techniques to replace the human expert. That expert system can suggest the best fit career(s) for the student by constructing a cognitive model for the student. That model generated by assessing various psychological factors viz. logical thinking, learning ability, decision making, patience, and perseverance, etc. solving the puzzle is one of the most suitable methods to assess them. The following provides an examination in this direction.

\section{Contributions in the field of Expert Systems}

In $\mathrm{AI}$, the expert system uses the knowledge domain stored in the computer to make a meaningful decision for the provided problem. It is a computer system that uses human knowledge and replaces the human expert. Application of expert system is in wide range viz. education, agriculture, medical, industry, etc.

Balasubramanyam, S. et al. [17] pointed out that the expert system resembles human expert knowledge. Chandra Prakash et al. [1] stated that the expert system replicates the behavior of a human expert, which helps to assess different types of psychological factors of persons for a particular purpose of classification. In this paper, they proposed an expert system for career guidance by using 8-puzzle solving.

Chandra Prakash V. et al. [2] proposed the expert system for assessing intelligence using Tic-Tac-Toe game playing. Many researchers suggested a much expert system for evaluating various behavior factors of people [3], [4], [5], [6], [7], [8], [9].

Chandra Prakash, V. et al. [14] pointed out that the expert system is a computer expert who tries reasoning by imitating the human expert. In this paper, the authors proposed the expert system for assessing the planning ability, logical thinking, learning ability and patience, and perseverance of a student.

\section{Contributions Cognitive Model}

Chandra Prakash V et al. [1] pointed out that the cognitive model simulates the psychological factors of the students' viz. speed of solving, learning the ability, intelligence, etc. The researcher suggested the system for evaluating factors by conducting the game called ' 8 - puzzle' for a student and builds the cognitive model of the student for suggesting a suitable career.

Aaron T Beck et al., [11] declared that the behavioural model of Beck was used to formulate and treat psychological disorders. The universal behavioural model is a collection of common concepts that can be useful across the mental illness continuum.

Lent, Robert Wet al. [10] stated two studies on the social cognitive model of self-management career presented for a career prediction and decision making factors in college students.

Prakash's Chandra et al. [2] suggested a system of experts playing Tic-Tac-Toe. The game Tic-Tac-Toe is smart. To battle against a machine, it requires the right amount of decision-making, intelligence, and patience, etc. for a 
student. The Expert system constructs a cognitive model by evaluating the psychological factors of the student. The cognitive model used for building the expert system predicts a suitable career(s) for the student.

\section{Career prediction (assessment)}

Steven K. Motswana et al. [12] pointed out that selecting the best suitable career(s) by the student is the crucial step that must be taken care of while opting for them. But major mistake doing by the student is following their known seniors for selecting their career(s), which may not suit most of them because of various factors. Therefore, an expert system needs development that can evaluate a student's ability and direct him/her in choosing the most suitable career.

Chathra Hendahewa et al. [13] created an Expert System of Career Advisory Program, called iAdvice, to direct students in their higher education to decide their career paths and choose their subjects in line with their career objectives. The expert system features such as alternative solutions with explanations, reasoning ability, measurement of probability, and providing uncertainty, and the ability to question found in iAdvice.

A number of expert models have been developed for assessing Psychological factors of a student's playing different games that include crypt arithmetic, Sudoku, Sokoban, memory power etc. [18][19][20][21][22][23][24][25][26][27]. Most of the models are built around human judgements for building the expert models. The expert model needs to be mined for experiential data stored in a database.

\section{ASSESSING PSYCHOLOGICAL FACTORS}

The student solves an array of times n-Coin Puzzle and reports the scores. Such ratings are analysed to determine the student's psychological factors in developing the student's cognitive model. The procedure that follows is acclimated.

\section{Evaluating Logical Thinking Ability}

The Expert System generates puzzles of increasing complexity depending on the level. These levels termed as Level 1 (4-Coin Puzzle), Level 2 (5-Coin Puzzle), and Level 5 (8-Coin Puzzle). The student has to solve puzzles of all levels. When a student completes the 4-coin puzzle, it assumed that the student passed at level 1 . To do this, he/she should make a minimum of 3 successful attempts. If the student solves a puzzle in 3 steps, then the student is awarded a score 2. if the student answers a puzzle in 4 steps, then the student is assigned a rating 1 else. It is zero. At each level, when a student completes that level, then only the student can enter the next level.

The expert system evaluates the logical thinking ability (LTA) of a student quantitatively using the following equation.

$$
\mathrm{LTA}=\sum_{l=1}^{5} \frac{\sum_{j=1}^{n_{l}} s_{j}}{n_{l}}
$$

Where 1 represents the level number,

$\mathrm{n}_{1}$ is a finite positive integer number $\left(\mathrm{n}_{1}>=3\right)$ that represents the number of attempts made by the student at the $1^{\text {th }}$ level. $S_{j}$ represents the score of a $j^{\text {th }}$ attempt at the $1^{\text {th }}$ level.

The Quantitative Score is converted to a qualitative score using the Table 1.

Table 1: Quantitative- Qualitative Conversion Table for Logical Thinking Ability

\begin{tabular}{|c|c|c|}
\hline $\begin{array}{c}\text { Serial } \\
\text { Number }\end{array}$ & Quantitative Score & Qualitative Score \\
\hline 1 & $>=8$ and $<=10$ & Very High \\
\hline 2 & $>=6$ and $<8$ & High \\
\hline 3 & $>=5$ and $<6$ & Moderate \\
\hline 4 & $>=2$ and $<5$ & Low \\
\hline 5 & $<2$ & Not Assessable \\
\hline
\end{tabular}

Evaluating Learning Ability:

The method followed by the expert system to assess the learning ability of a student is as follows. An excellent student can complete a level in a minimum of three attempts, whereas an average student may need more effort to complete the level. Hence the learning ability (LA) is inversely proportional to the number of attempts $\left(\mathrm{n}_{1}\right)$ made by a student to achieve a level of competence. The complexity involved in solving puzzles at level 1 is very low, whereas the complexity involved in solving problems at level 5 is very high. Hence, a weighting factor $\left(\mathrm{w}_{1}\right)$ assigned to each level. The learning ability of a student is computed using the following equation.

$$
\mathrm{LA}=\sum_{l=1}^{5} w_{l} *\left(3 / N_{l}\right) .
$$

This formula is illustrated using Table 2. Table 3 shows the quality assessment method relating to Learning ability of the students.

Table 2: Learning Ability Calculation.

\begin{tabular}{|c|c|c|c|}
\hline Level & $\begin{array}{c}\text { Weighting } \\
\text { Factor } \\
\text { (wi) }\end{array}$ & $\begin{array}{c}\text { Number } \\
\text { of } \\
\text { Attempt } \\
\mathbf{S} \\
(\mathbf{N})\end{array}$ & $\begin{array}{c}\text { Learning Ability } \\
\mathbf{W}_{\mathbf{l}} *\left(\mathbf{3} / \mathbf{N}_{\mathbf{l}}\right)\end{array}$ \\
\hline $\mathbf{1 .}$ & $\mathbf{0 . 5 0}$ & $\mathbf{N}_{\mathbf{1}}$ & $0.50 *\left(3 / \mathrm{N}_{1}\right)$ \\
\hline $\mathbf{2 .}$ & $\mathbf{0 . 7 5}$ & $\mathbf{N}_{\mathbf{2}}$ & $0.75 *\left(3 / \mathrm{N}_{2}\right)$ \\
\hline $\mathbf{3 .}$ & $\mathbf{1 . 0 0}$ & $\mathbf{N}_{\mathbf{3}}$ & $1.00 *\left(3 / \mathrm{N}_{3}\right)$ \\
\hline $\mathbf{4 .}$ & $\mathbf{1 . 2 5}$ & $\mathbf{N}_{4}$ & $1.25 *\left(3 / \mathrm{N}_{4}\right)$ \\
\hline $\mathbf{5 .}$ & $\mathbf{1 . 5 0}$ & $\mathbf{N}_{\mathbf{5}}$ & $1.50 *\left(3 / \mathrm{N}_{5}\right)$ \\
\hline & & $T^{2}$ Total & $\sum_{l=1}^{l=5} w_{l} *\left(3 / N_{l}\right)$ \\
\hline
\end{tabular}


V. Chandra Prakash et al., International Journal of Emerging Trends in Engineering Research, 7(11), November 2019, 410 - 416

Table 3: Quantitative- Qualitative Conversion Table for Learning Ability.

\begin{tabular}{|c|c|c|}
\hline $\begin{array}{c}\text { Seral } \\
\text { Number }\end{array}$ & Quantitative Score & Qualitative Score \\
\hline 1 & $>=0$ and $<=1$ & Low \\
\hline 2 & $>1$ and $<=2$ & Moderate \\
\hline 3 & $>2$ and $<=3$ & Good \\
\hline 4 & $>3$ and $<=4$ & Very Good \\
\hline 5 & $>4$ and $<=5$ & Excellent \\
\hline
\end{tabular}

\section{Evaluating Patience and Perseverance:}

The method followed by the expert system to assess the patience and perseverance of a student is as follows. Hence patience and persistence are directly proportional to several attempts $\left(\mathrm{n}_{1}\right)$ and several levels completed. The level of patience and perseverance involved in solving puzzles at level 1 is very low, whereas the patience and perseverance required in solving puzzles at level 5 are very high. Hence, a weighting factor $\left(\mathrm{w}_{\mathrm{l}}\right)$ assigned to each level. The patience and determination of a student are computed using the following equation.

$$
\mathrm{PP}=\sum_{l=1}^{5} n_{l} * w_{l}
$$

This formula is illustrated using Table -4 . The expert system converts into patience and perseverance (qualitative) using Table-4 and Table-5.

Note: Ceiling value means a maximum number of attempts considered in the level for calculating the score. For example, if a student attempted $\left(A_{i}\right)$ less than ceiling value $\left(B_{i}\right)$, then $n_{i}=A_{i}$ if not, then $n_{i}=B_{i}$.

Table 5 :Patience and Perseverance Conversion Table.

\begin{tabular}{|c|c|c|}
\hline $\begin{array}{c}\text { Seral } \\
\text { Number }\end{array}$ & Quantitative Score & Qualitative Score \\
\hline 1 & $>=40$ & Excellent \\
\hline 2 & $>=30$ and $<40$ & Very Good \\
\hline 3 & $>=20$ and $<30$ & Good \\
\hline 4 & $>=10$ and $<20$ & Moderate \\
\hline 5 & $<10$ & Low \\
\hline
\end{tabular}

\section{Predicting Suitable Career(s)}

Usually, C.G.P.A. of a student considered for selecting a suitable career(s). CGPA shows the academic excellence of the student, but we suggest that, apart from the CGPA of the student, different psychological factors considered when selecting the appropriate career for the student. Some of the occupation (s) in the software industry are identified and mentioned in the Table-6. CGPA and levels of different psychological factors needed to match the job.

Earlier, the student had assessed various psychological factors quantitatively using n-Coin Puzzle and converted it into qualitative. A comparing process is conducted to compare and match the different levels of psychological factors of the students with needed levels of factors of each career (see Table 6) and recommend the proper job (s). A Report shows a suitable career(s) to the students.

\section{RESULTS AND DISCUSSIONS}

Some sample sets of students selected from computer science and engineering. They solved $\mathrm{n}$-coin puzzles that are provided by the expert system. The expert system assessed the psychological factors of the student quantitatively and qualitatively. Based on the evaluated psychological factors, the expert system found the most suitable career(s) for the students. Table 7 shows the predicted results.

In general, we can expect that a student who exhibits good logical thinking ability will also get a good score in his/her course(s) of study viz - Java Programming, C Programming, etc. similarly, if a student maintains an excellent rating in courses(s) viz. Java Programming, C Programming, etc. we can expect that his/her logical thinking ability is high, and he/she can perform well in solving n-coin puzzles. But in some rare cases, the proposed hypothesis may be violated.

The score relating to logical thinking ability is computed by the expert system and the academic scores in java programming of students shown in Table 8. A graph plotted by taking the scores inconsistent thinking ability on the $\mathrm{x}$ axis and the scores in java programming on the y-axis, as shown in Figure 1.

In the graph shown in Figure 1 one can observe that some students who have high scores in logical thinking ability have secured fewer scores in a java programming course. The reason for this anomaly may be that students did not show much interest in their academic courses.

Table 8: Scores in Logical Thinking Ability and Java Programming.

\begin{tabular}{|c|l|c|c|}
\hline $\begin{array}{c}\text { Serial } \\
\text { Number }\end{array}$ & $\begin{array}{c}\text { Register } \\
\text { Number }\end{array}$ & $\begin{array}{c}\text { Logical } \\
\text { Thinking } \\
\text { Ability }\end{array}$ & $\begin{array}{c}\text { Score in Java } \\
\text { Programming } \\
\text { (max 10) }\end{array}$ \\
\hline 1. & 30478 & 2.5 & 6.0 \\
\hline 2. & 30988 & 3.2 & 4.0 \\
\hline 3. & 30259 & 3.8 & 5.5 \\
\hline 4. & 31040 & 5.3 & 7.3 \\
\hline 5. & 30624 & 5.7 & 8.0 \\
\hline 6. & 30888 & 6.2 & 4.2 \\
\hline 7. & 30540 & 6.7 & 8.2 \\
\hline 8. & 31326 & 7.2 & 5.2 \\
\hline 9. & 31322 & 7.9 & 8.5 \\
\hline 10. & 30456 & 8.7 & 9.2 \\
\hline 11. & 31247 & 9.0 & 9.3 \\
\hline
\end{tabular}




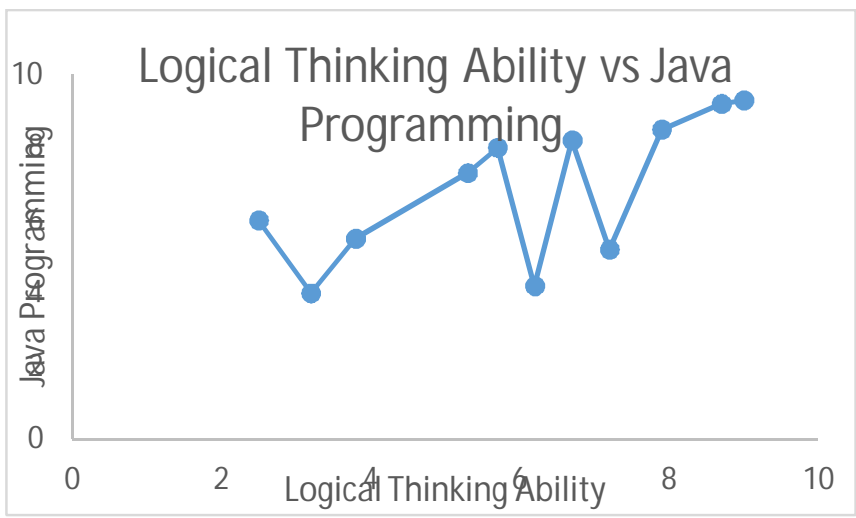

Figure 1: Logical Thinking Ability vs. Java Programming.

Similarly, some students who obtained low scores in logical thinking ability have high scores in a java programming course as shown in Table 9. The reason for this anomaly may be that the student possesses moderate, consistent thinking ability, but they are diligent, hard workers with good memory power, and hence, they might have secured high scores in java programming. These two types of odd students, termed as outliers. By elimination the ratings of these outlier students, a graph plotted shown in figure 2.

Table 9: Updated Scores in Logical Thinking Ability and Java Programming.

\begin{tabular}{|c|l|l|l|}
\hline $\begin{array}{l}\text { Serial } \\
\text { Number }\end{array}$ & $\begin{array}{l}\text { Registration } \\
\text { number }\end{array}$ & $\begin{array}{l}\text { Logical } \\
\text { Thinking } \\
\text { Ability } \\
\text { (Max 10) }\end{array}$ & $\begin{array}{l}\text { Java } \\
\text { Programming } \\
\text { Score } \\
\text { (max 10) }\end{array}$ \\
\hline 1. & 30988 & 3.2 & 4.0 \\
\hline 2. & 30259 & 3.8 & 5.5 \\
\hline 3. & 31040 & 5.3 & 7.3 \\
\hline 4. & 30624 & 5.7 & 8.0 \\
\hline 5. & 30540 & 6.7 & 8.2 \\
\hline 6. & 31322 & 7.9 & 8.5 \\
\hline 7. & 30456 & 8.7 & 9.2 \\
\hline 8. & 31217 & 9.0 & 9.3 \\
\hline
\end{tabular}

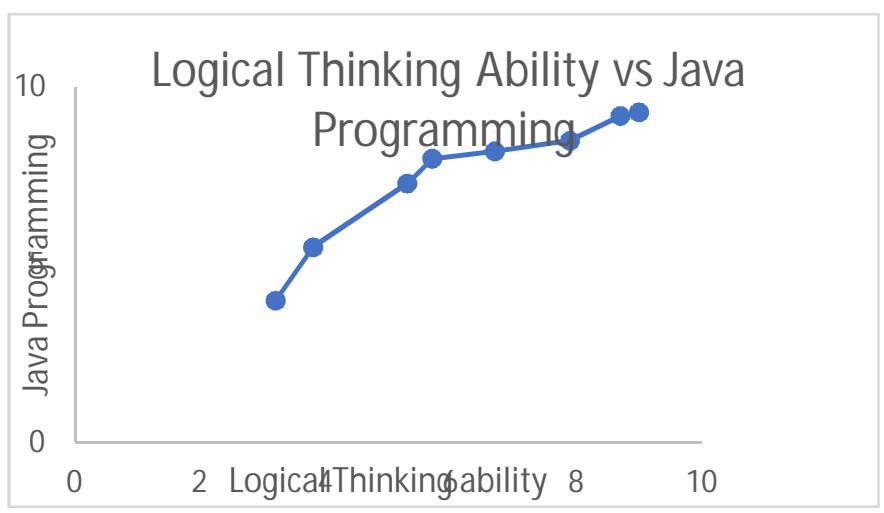

Figure 2 :Updated Logical Thinking Ability vs. Java Programming.
This process establishes a relation between logical thinking ability and Java Programming. i.e., In general, students having good logical thinking ability have excellent academic records in the course(s) like $\mathrm{C}, \mathrm{C}++$, Java Programming that requires consistent thinking ability.

\section{CONCLUSIONS}

The expert system that uses n-Coin Puzzle for career(s) prediction tested thoroughly, and it was found to be very useful in evaluating the psychological factors of some final year students of B.Tech program in computer science and engineering. A graph plotted that established the correlation between the logical thinking ability of students assessed through the n-coin puzzle and the consistent thinking ability indicated through the scores in a java programming course.

\section{ACKNOWLEDGMENT}

This exploration work is a part of a research project entitled "Development of an Expert System for career assessment based on the cognitive model." funded by the Department of Science and Technology-Cognitive Science Research Initiative Scheme(CSRI) (Sanction Order No SR / CSRI/129/2014(G)) of the Government of India. Dr. V. Chandra Prakash is the project's Principal Investigator. K L (Deemed to be) University facilitates the infrastructure for the project.

\section{REFERENCES}

1. V. Chandra Prakash, J. K. R. Sastry "Expert system for building a cognitive model of a student using the 8-puzzle game and for career assessment." International Journal of Engineering \& Technology, vol-7(2.27), 113-117, 2018 https://doi.org/10.14419/ijet.v7i2.27.12014

2. Prakash, V. Chandra, J. K. R. Sastry, B. Mohana Priyanka, K. Pavan Kuma, Ch Deepika, and N. Pavan Kalyan Yadav. "Assessing the Intelligence of a student through the Tic-Tac-Toe Game for Career Guidance." International Journal of Pure and Applied Mathematics 117, no. 16, 565-572., 2017

3. Prakash, V. Chandra, J. K. R. Sastry, V. Kantharao, V. Sriharshini, G. Sriram, and C. H. V. S. Ganesh. "An Expert System to assess the memory power of a student for selection of a suitable career." Journal of Advanced Research in Dynamical and Control Systems

4. Manisha L Waghmode, P PJamsandekar, Expert system for Career Selection: Theoretical Framework, International Journal of Computer Science, Volume 4, Issue 8, 2321-5992, 2016

5. El Haji, Essaid, Abdellah Azmani, and Mohamed El Harzli. "Multi-expert system design for educational and career guidance: an approach based on a multiagent system and ontology." International Journal of Computer Science Issues (IJCSI) 11, no. 5, 46., 2014 
https://doi.org/10.1109/ICMCS.2014.6911256

6. Saraswathi, S., M. Hemanth Kumar Reddy, S. Udaya Kumar, M. Suraj, and Sk Khaja Shafi. "Design of an online expert system for career guidance." The International Journal of Research in Engineering and Technology, 3, 2014.

7. Ezenkwu, C. P., E. H. Johnson, and O. B. Jerome. "Automated Career Guidance Expert System Using Case-Based Reasoning."; Computing, Information Systems, Development Informatics \& Allied Research Journal, 2015

8. Athanasios Drigas, Stelios Kouremenos, Spyros Vrettos, John Vrettaros, and Dimitris Kouremenos. "An Expert system for job matching of the unemployed." Expert Systems with Applications26, no. 2 217-224. https://doi.org/10.1016/S09574174(03)00136-2, 2014.

9. Essaid El Haji, Abdellah Azmani, and Mohamed El Harzli. "Expert system design for educational and vocational guidance, using a multi-agent system." In Multimedia Computing and Systems (ICMCS), 2014 International Conference on, pp. 1018-1024. IEEE, 2014.

10. Lent, Robert W., Ijeoma Ezeofor, M. Ashley Morrison, Lee T. Penn, and Glenn W. Ireland. "Applying the social cognitive model of career selfmanagement to career exploration and decisionmaking." Journal of Vocational Behavior, 47-57. https://doi.org/10.1016/j.jvb.2015.12.007, 2016.

11. Beck, Aaron T., and Emily AP Haigh. "Advances in cognitive theory and therapy: the generic cognitive model." Annual review of clinical psychology, 124. https://doi.org/10.1146/annurev-clinpsy032813-153734, 2014

12. Steven K. Mtsweni and Johnson O. Dehinbo. "Development and Usability of a Web Application for Career Choice for High School Students." In Proceedings of the World Congress on Engineering and Computer Science, vol. 1. 2013.

13. Chathra Hendahewa, Maheshika Dissanayake, Artificial Intelligence approach to useful Career Guidance, Sri Lanka Association for Artificial Intelligence, 2006

14. Chandra Prakash, V., Sastry, J. K. R., A critical study on the applicability of the Sokoban game for building a cognitive model of a student for career assessment. International Journal of Engineering \& Technology, 7 (1.1), 260-264, 2018

15. Chandra Prakash, V., Sastry, J. K. R., Applicability of Sudoku game for building the cognitive model of a student for career assessment - an analytical study. International Journal of Engineering \& Technology, 7 (1.1) (2018) 246-251, 2018.

16. Sripath Roy, K., Roopkanth, K., Uday Teja, V., Bhavana, V., \& Priyanka, J., Student career prediction using advanced machine learning techniques. International Journal of Engineering and Technology (UAE), 7(2), 26-29, 2018.
17. Balasubramanyam, S., Padmaja Usharani, D., Harsha Vardhan Reddy, A., Swetha, D., Kumar, G. N. S., Anusha, K., \& Ahammad, S. H.. Selecting a college academic branch-A design decision-taking system for student career selection. International Journal of Engineering and Technology (UAE), 7(4.19 Special Issue 19), 323-328, 2018.

18. Sasi Bhanu, J., Sastry, J.K.R., Sunitha Devi, B., Chandra Prakash, V. Career Guidance through TOC-TOC-TOE Game, International Journal of Emerging Trends in Engineering Research 7(6), pp. 25-31, 2019 https://doi.org/10.30534/ijeter/2019/01762019

19. Prakash, V.C., Kantharao, V., Sastry, J.K.R., Chandrika, V.B., Expert system for building a cognitive model of a student using crypt arithmetic game and for career assessment, International Journal of Recent Technology and Engineering 7(6), pp. 146-151, 2019

20. Chandra Prakash, V., Kantharao, V., Sastry, J.K.R., Bala Chandrika, V., Expert System for Building the cognitive model using crypt arithmetic game and for career guidance, International journal of recent Technology and Engineering, 7(6), pp.684-689, 2019

21. Bhanu, J.S., Sastry, J.K.R., Prakash, V.C., Assessing the intelligence of a student through tictac-toe game for career guidance, International Journal of Electrical and Computer Engineering 9(6), pp. 5545-5551, 2017 https://doi.org/10.11591/ijece.v9i6.pp5545-5551

22. V. Chandra Prakash, J. K. R. Sastry, V. Kantharao, V. Sriharshini, G. Sriram, and C. H. V. S. Ganesh. "An Expert System to assess memory power of a student for selection of a suitable career," Journal of Advanced Research in Dynamical and Control Systems, 9(6), 309-321. 2017

23. Sasi Bhanu J, Sastry JKR, On Building cognitive expert system for managing road traffic within smart cities, Ponte, 73(7), pp. 98-109, 2017 https://doi.org/10.21506/j.ponte.2017.7.38

24. Kamesh D.B.K, Sumadhuri DSK, Sahithi MSV, Sastry JKR, Journal of Engineering and Applied Sciences, 12(9), pp.2437-2445, 2016

25. Sasi Bhanu J, Sreeharsha KVS, Vyshnavi K, Sastry JKR, Composite messaging systems management systems for traffic management in smart cities, Journal of Engineering and Applied Sciences, 11(10), pp. 2286-2293, 2016

26. Sastry JKR, Naveena Muralidhar T, Lakshmi Chandana Y, Sasi Bhanu J, A composite remote sensing and monitoring method for effective traffic management, Journal of Engineering and applied sciences, 11(11), pp. 2535-2544, 2016

27. Sastry JKR, Devishushma, Aslesh Y, Sasi Bhanu J, Visualisation method for effective traffic management within smart cities, Journal of engineering and applied sciences, 11(7), pp. 15981605,2018 
V. Chandra Prakash et al., International Journal of Emerging Trends in Engineering Research, 7(11), November 2019,410 - 416

Table 4: Patience and Perseverance Calculation.

\begin{tabular}{|c|c|c|c|c|c|}
\hline Level & $\begin{array}{l}\text { Number of attempts } \\
\qquad\left(\mathbf{A}_{\mathbf{i}}\right)\end{array}$ & $\begin{array}{c}\text { Ceiling value } \\
\left(\mathbf{B}_{\mathbf{i}}\right)\end{array}$ & $\begin{array}{c}\text { Number of } \\
\text { attempts } \\
\left(\mathbf{N}_{\mathbf{i}}\right) \\
\end{array}$ & $\begin{array}{l}\text { Weighting factor } \\
\qquad\left(\mathbf{W}_{\mathbf{i}}\right)\end{array}$ & $\begin{array}{c}\text { Score } \\
\left(\mathbf{N}_{\mathbf{i}} * \mathbf{W}_{\mathbf{i}}\right)\end{array}$ \\
\hline 1. & $\mathbf{A}_{1}$ & 10 & $\mathbf{N}_{1}$ & 1.0 & $\mathrm{~N}_{1} * \mathrm{~W}_{1}$ \\
\hline 2. & $\mathbf{A}_{2}$ & 20 & $\mathbf{N}_{2}$ & 1.5 & $\mathrm{~N}_{2} * \mathrm{~W}_{2}$ \\
\hline 3. & $\mathbf{A}_{3}$ & 20 & $\mathbf{N}_{3}$ & 2.0 & $\mathrm{~N}_{3} * \mathrm{~W}_{3}$ \\
\hline 4. & $\mathbf{A}_{4}$ & 20 & $\mathbf{N}_{4}$ & 2.5 & $\mathrm{~N}_{4} * \mathrm{~W}_{4}$ \\
\hline 5. & $\mathbf{A}_{5}$ & 20 & $\mathbf{N}_{5}$ & 3.0 & $\mathrm{~N}_{5} * \mathrm{~W}_{5}$ \\
\hline & & & & Total & $\sum_{i=1} N_{l} * W_{l}$ \\
\hline
\end{tabular}

Table 6: Job Table with minimum levels of psychological factors

\begin{tabular}{|c|l|l|l|l|l|}
\hline $\begin{array}{c}\text { Serial } \\
\text { Number }\end{array}$ & \multicolumn{1}{|c|}{ Job } & \multicolumn{1}{|c|}{ CGPA } & $\begin{array}{c}\text { Minimum } \\
\text { Logical } \\
\text { Thinking } \\
\text { Ability }\end{array}$ & $\begin{array}{c}\text { Minimum } \\
\text { Minimum } \\
\text { Latience and } \\
\text { perseverance }\end{array}$ \\
\hline 1. & Marketing Person & $>=5.0$ & Low & Low & Excellent \\
\hline 2. & Software Tester & $>=7.0$ & Moderate & Moderate & Very good \\
\hline 3. & Software Maintenance Engineer & $>=7.5$ & High & Good & Very Good \\
\hline 4. & Software Engineer & $>=8.0$ & Very High & Very Good & Very Good \\
\hline
\end{tabular}

Table 7 :Student vs. Predicted Career(s).

\begin{tabular}{|c|l|l|l|l|l|c|c|}
\hline $\begin{array}{c}\text { Serial } \\
\text { Number }\end{array}$ & $\begin{array}{c}\text { Register } \\
\text { Number }\end{array}$ & $\begin{array}{c}\text { CGPA } \\
\text { (Max 10) }\end{array}$ & $\begin{array}{c}\text { Logical } \\
\text { Thinking } \\
\text { Ability }\end{array}$ & $\begin{array}{l}\text { Patience and } \\
\text { perseverance }\end{array}$ & $\begin{array}{c}\text { Learning } \\
\text { Ability }\end{array}$ & $\begin{array}{c}\text { Highest predicated } \\
\text { career } \\
\text { Programing }\end{array}$ & $\begin{array}{c}\text { Score in } \\
\text { JVA }\end{array}$ \\
\hline 1. & 31322 & 8.0 & High & Moderate & Good & Software tester & 8.5 \\
\hline 2. & 30456 & 9.0 & Very High & High & Very hood & Software engineer & 9.2 \\
\hline 3. & 30478 & 9.0 & Low & Very High & Moderate & Marketing person & 6.0 \\
\hline 4. & 31040 & 7.0 & Moderate & High & Good & Software Tester & 7.3 \\
\hline
\end{tabular}

